\title{
IMPROVING SPATIAL ABILITY SKILLS OF FIRST-YEAR STUDENTS IN BASIC ENGINEERING DRAWING USING A SOLID PAIR MODEL
}

\author{
${ }^{* 1}$ Marwa, N. J., ${ }^{2}$ Choji, J. and ${ }^{3}$ Dalumo, B. D.
}

\author{
${ }^{*}$ Department of Technical Education Kaduna State College of Education, Gidan waya, Kafanchan, Kaduna State, Nigeria. \\ *Phone: +2348039583770*Email: njohn5574@gmail.com \\ ${ }^{2}$ Department of Science and Technology Education, Faculty of Education, University of Jos, Nigeria. \\ Phone: 08036276895, Email: dung_choji@yahoo.com \\ ${ }^{3}$ Faculty of Built Environment and Surveying, Unversiti Teknologi Malaysia \\ Phone: +234163278060, Email: b.dalumo@graduate.utm.my
}

\begin{abstract}
Good spatial ability skills are an important component of an engineer's ability to create and interpret engineering drawings, which is demanding in thinking, being a problem-solving process. The ability of an engineer to visualize in 3D is a cognitive skill that is attached to success in basic engineering drawing subjects. Engineering and technology education students need good spatial ability skills to understand several topics in basic engineering drawings like orthographic projection, axonometric drawing, sectional view, and hidden details drawings. This study aims at improving spatial ability skills using a solid pair model among first-year technical education students of Kaduna State College of Education Gidan Waya. A Quasi-experimental research design was used for the study, a standards pre and post-test were used to conduct a visualization transformation assessment to measure the students' level of spatial ability skills. The study shows that after treatment using a solid pair model, the student without prior knowledge in basic engineering performed above average, likewise students with prior knowledge in the control and experimental group performed above average. The results indicate that a solid pair model was effective for improving spatial ability skills among first-year technical education students. This study implies to educators that there is need to appropriately enforce the use of a solid pair model for effective teaching and learning of basic engineering drawing. It is, therefore, affirmed that the use of a solid pair model in teaching basic engineering drawings should be enhanced with other teaching methods.
\end{abstract}

Keywords: engineering drawing, enhancement, skills, solid pair model, spatial ability 


\section{INTRODUCTION}

Spatial ability skill is referred to as a trait in human intelligence which is a vital and very important fundamental skill in the engineering and technology field (Kok and Bayaga 2019). According to Nagy-kondor (2007), the ability of an individual to manipulate or transform the patterns and image of an object into other shapes or form of arrangement is referred to as spatial ability. Kösa and Karaku, (2010) stated that the ability to imagine a picture and manipulate the image of an object mentally is called spatial ability. However, it specifically deals with the manipulation of 2D or 3D objects mentally.

The need to communicate ideas in architecture, mechanical engineering, civil engineering, and other engineering disciplines is a basic necessity where all efforts of engineering drawing for technological advancement are hinged on to satisfy the basics of translating such ideas. The need for technical drawing becomes very demanding in such a way that, no production or manufacturing can be successfully done without a neat and detail drawing to show the relationship between components, joints, and other linkages.

Lois (2017) stated that engineering drawing is used for communicating ideas, thoughts, and designs. Generally, it provides detailed information about the shape, size, surface quality, material, tolerance, and manufacturing process of the design. Bertoline et al., (2013) define drawing as a graphical representation of objects and structure. Drawing may be abstract and may become very complicated because of the existence of so many parts. In times of mass production, such parts are used interchangeably from one section to another. For easy identification of each part, engineering drawing is used with sufficient precision for the production.

Moreno-garc1 (2019) defines engineering drawing as a schematic representation of an idea, an object, or a circuit showing in detail the relationship, the flow, and the constituents of such object or circuit. An example of such a drawing includes mechanical drawing and architectural drawing. For an engineer to successfully draw and define the flow of an object or a circuit, he or she needs to have good spatial ability skills Buckley et al., (2019).

According to Rodriguez and Rodriguez-velazquez, (2017) appropriate instructional aides have proven to have a good significant effect in improving student's spatial ability skills. Azman (2015) highlighted that instructors' and learners' attitudes are recommendable in learning skills towards digital technologies. A similar study by Hughes et al., (2017) shows the need for a significant score of instructors' computer efficiency for improving teaching and learning of technical drawing. Maudsley et al., (1999) in their research concluded that using an instructional model approach for teaching and learning improves students' performance as well as other counterparts. As a technical teacher, one will not only want his students to learn technical drawing but also embrace the knowledge and approaches for solving a problem. Savery (2006) stated that learners will become proficient in conducting research and integrating theory practices by applying knowledge and skills to develop a viable solution in defining problems using an instructional model approach which is a curricular based methodology for teaching and learning problems.

Alias et al., (2002) strengthened that spatial ability skills are an important component in engineering drawing because it is an ability to effectively communicate through lines, graphics, and symbols which is a compulsory unique method to explain an idea.

According to Adanez and Velasco, (2004) engineering and technology students face many challenges in engineering drawing which are attributed to poor spatial ability skills and the inability for the students to draw 
orthographic views of an isometric block. These factors could also be attributed to inadequate facilities, methodology, instructional aides, or an inadequate number of hours per class.

In assessing technology and engineering students' performance in engineering drawing, Ghanat and Brown (2017) stated that a positive outcome using instructional aides promotes learning. According to Ghanat and Brown (2017) after conducting a research reported that $75 \%$ achievement was recorded from student's performance tests using instructional aides which were rated effective and very efficient in promoting teaching and learning of engineering drawing. Ramona (2013) researched that enhancing students' spatial ability is a needed skill that promotes the competency of students in fundamentals of basic engineering drawing, the projection of views, and shapes of compacting components before fabrication or manufacturing.

Spatial ability skills are critical skills required by engineering students for problem-solving and modelling in engineering drawings (Serdar 2015). The importance of spatial ability skills in engineering and technology education has attracted many scholars in the field of science and technology to search into ways of improving visualization skills among students (Katsioloudis et al., 2014). Interestingly, 3D tools and augmented reality could be an important tool, where when appropriately used, able to improve students' spatial ability skills (Medina et al., 2019). According to Marunić and Glažar (2014), the inability of the students to visualize the elevations of an isometric block from 2D is a component of spatial ability skills.

\section{OBJECTIVE OF THE STUDY}

The study aims to:

1. measure the effectiveness of a solid model for improving spatial ability skills in basic engineering drawing.

2. find out whether there a significant improvement of spatial ability skills using a solid model in teaching basic engineering drawing.

\section{RESEARCH QUESTION}

The following research questions were formulated in line with the purpose of the study to guide the study.

1. What the effectiveness of a solid pair model in improving spatial ability skills in basic engineering drawing?

2. What is the level of spatial ability skill improvement between the students who had prior knowledge of engineering drawing from secondary school and those who did not?

\section{METHODOLOGY}

A quasi-experimental research design was used for the study. A targeted class of 28 students who were in first-year and first semester in the department of technical education Kaduna state college Gidan Waya Kafanchan were used for the study. The class was separated into two groups which were: Control group and Experimental group. In the first instance, the teacher initially identified 13 students who had prior knowledge in technical drawing from secondary school. And 18 students who did not have prior knowledge of engineering drawing from secondary school. A nonpurposive probability sampling technique was used to separate the students into the control and experimental group (Centre 2011). 
A two and three-dimensional shapes instrument for visualization transformation test by French 1978 was adapted for the study. Korb (2013) stated that, when an instrument is adapted for a research study, its reliability and validity will be based on research that has been conducted using the same instrument which can be applied to the current study. The validity and reliability of the instrument was tested on a study conducted on the spatial ability of engineering students by Nagy-kondor (2007). A pre and post-test was used to collect the data from the students. To avoid the issues of data contamination, and since prior knowledge might temper the result of the pre and post-test, it was important to first identify the students with and without prior knowledge, the pre and post-test were taking simultaneously between the control and experimental groups.

The class activities during the data collection for the pre and post-test are illustrated in figure 1 below.

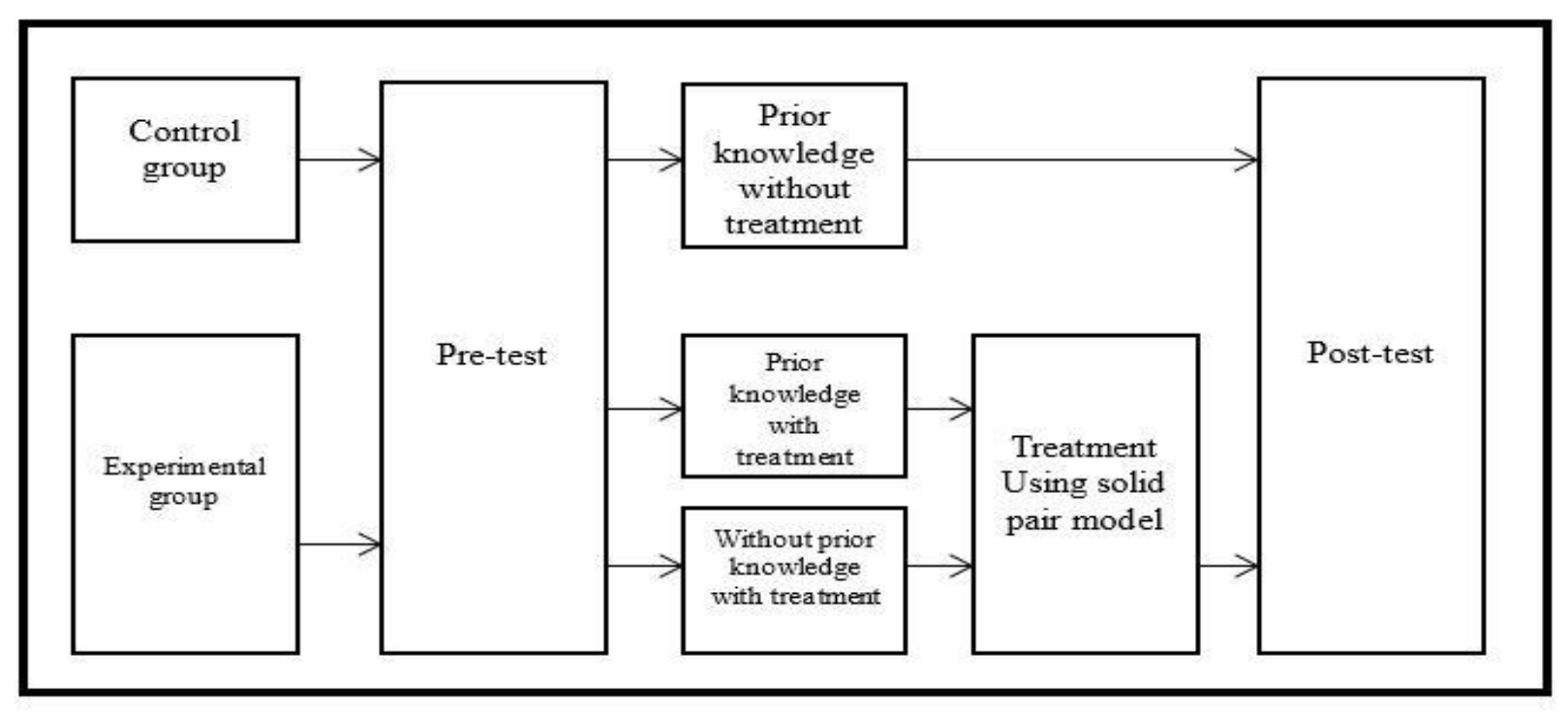

Figure 1: flow chat of pre and post-test activities

For the pre-test, all the students were taught using the conventional method of teaching and learning of basic engineering drawing, as presented below. 


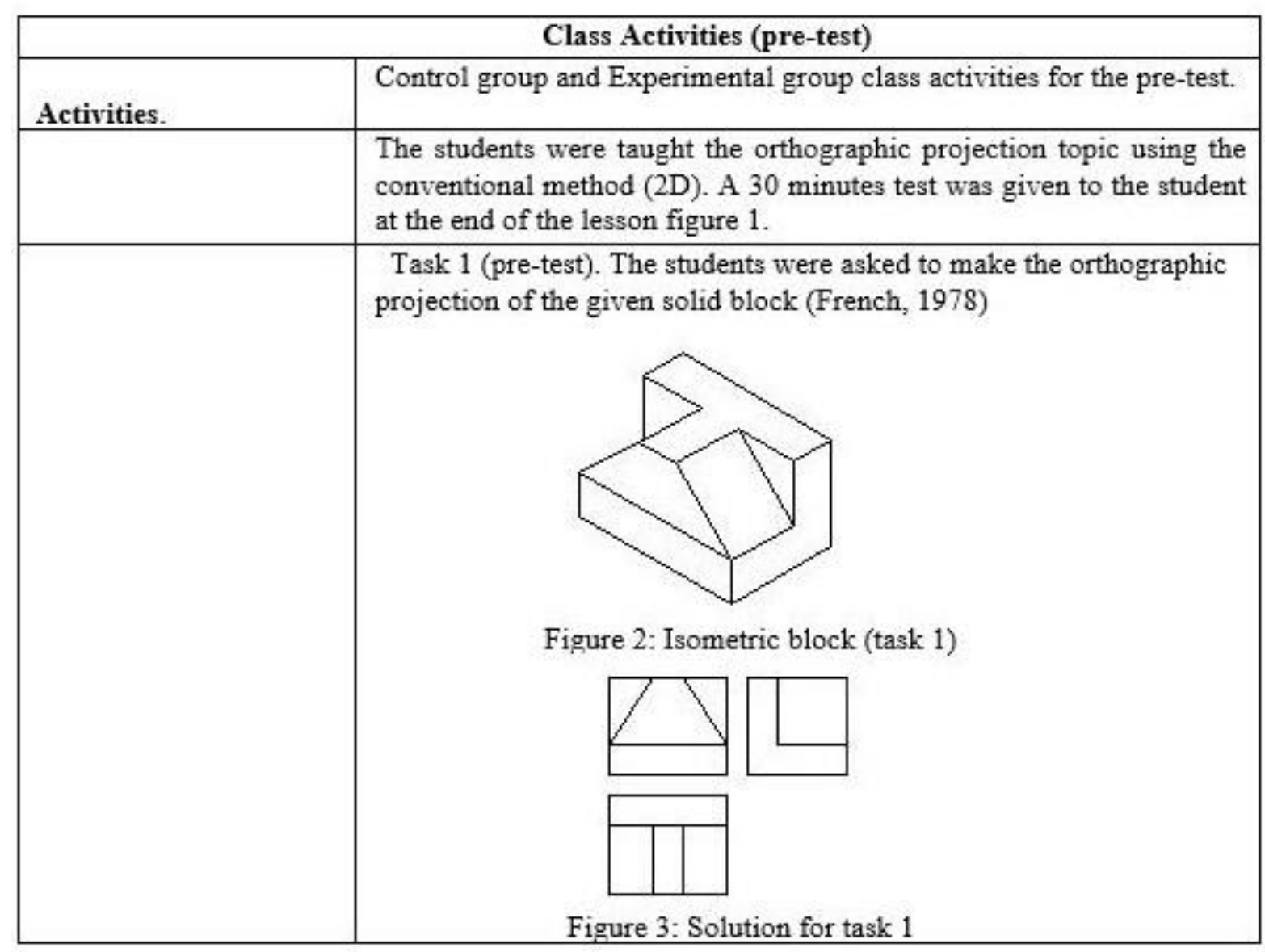

At the second stage of data collection, a period of six weeks was given between the pre and post-test (Bate and Karp 2014). At this stage, the students were separated into three groups, the first category was: students who had prior knowledge of engineering drawing without treatment, the second group were students who have prior knowledge of engineering drawing with treatment and the third group were students who did not have prior knowledge of engineering drawing with treatment. The students who formed the second and third groups were separated into the experimental group while the first category of the students formed the control group. The experimental group was taught using the solid pair model while the control group was taught using the traditional method of teaching basic engineering drawing. at the end of the lesson, a post-test was conducted. 


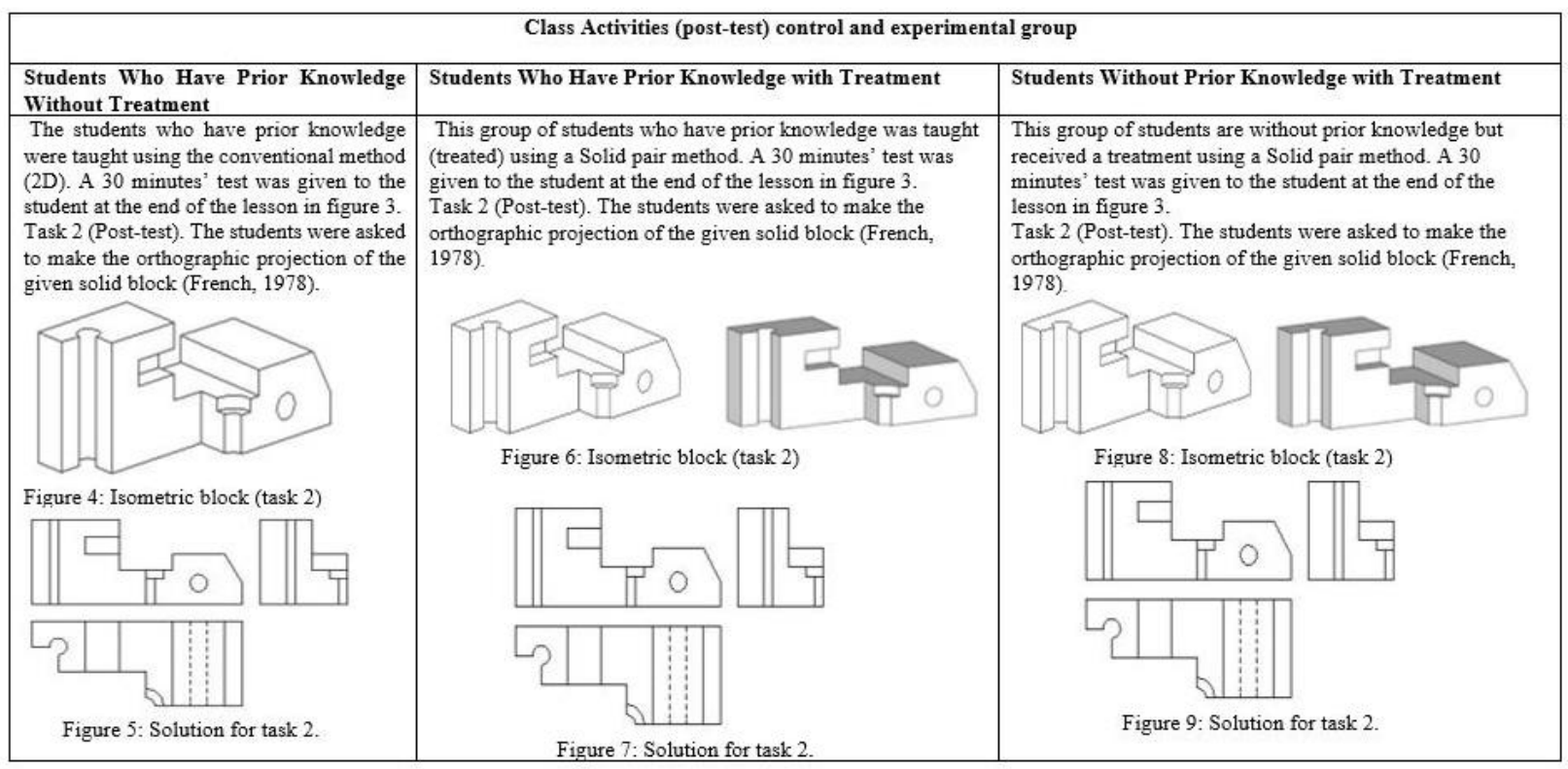

\section{RESULTS}

The data were analyzed using Statistical Package for Social Sciences (SPSS) software. The performance of the students was presented accordingly. The first group consisting of students who had prior knowledge of engineering drawing from secondary school. These students were taught using the conventional method at the post pest. The lowest score obtained for this group was 30\% and the highest score was $80 \%$ in the pre-test, and the lowest score of $40 \%$ and highest score $80 \%$ in the post-test as presented in figure 1.

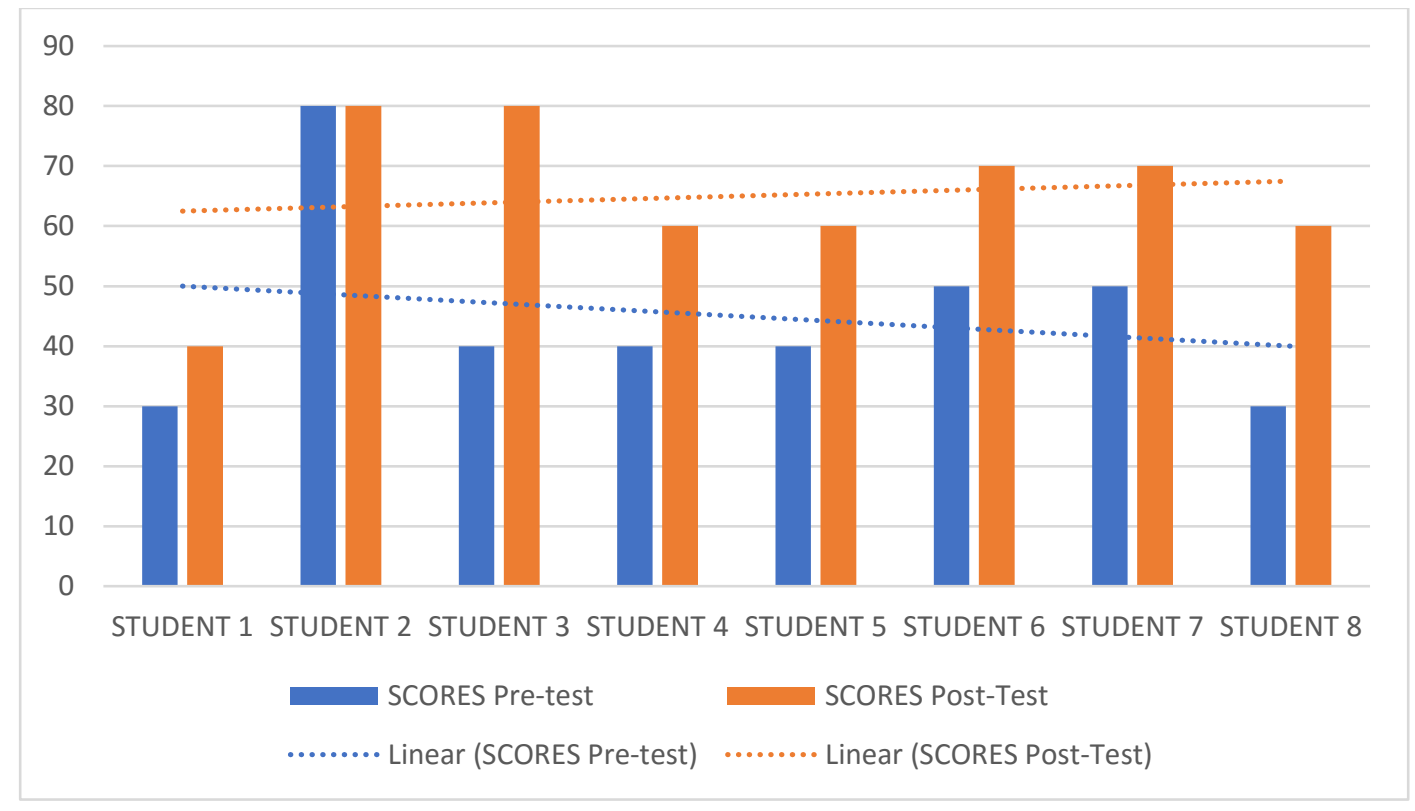

Figure 1: VTT performance for students who have prior knowledge without treatment 
The second group comprised of students who and prior knowledge of basic engineering drawing from secondary school who were exposed to treatment, this group of students had the lowest score of $20 \%$ and the highest score of $80 \%$ in the pre-test, while in the post-test they had the lowest score of $40 \%$ and a higher score of $80 \%$ as represented in figure 2.

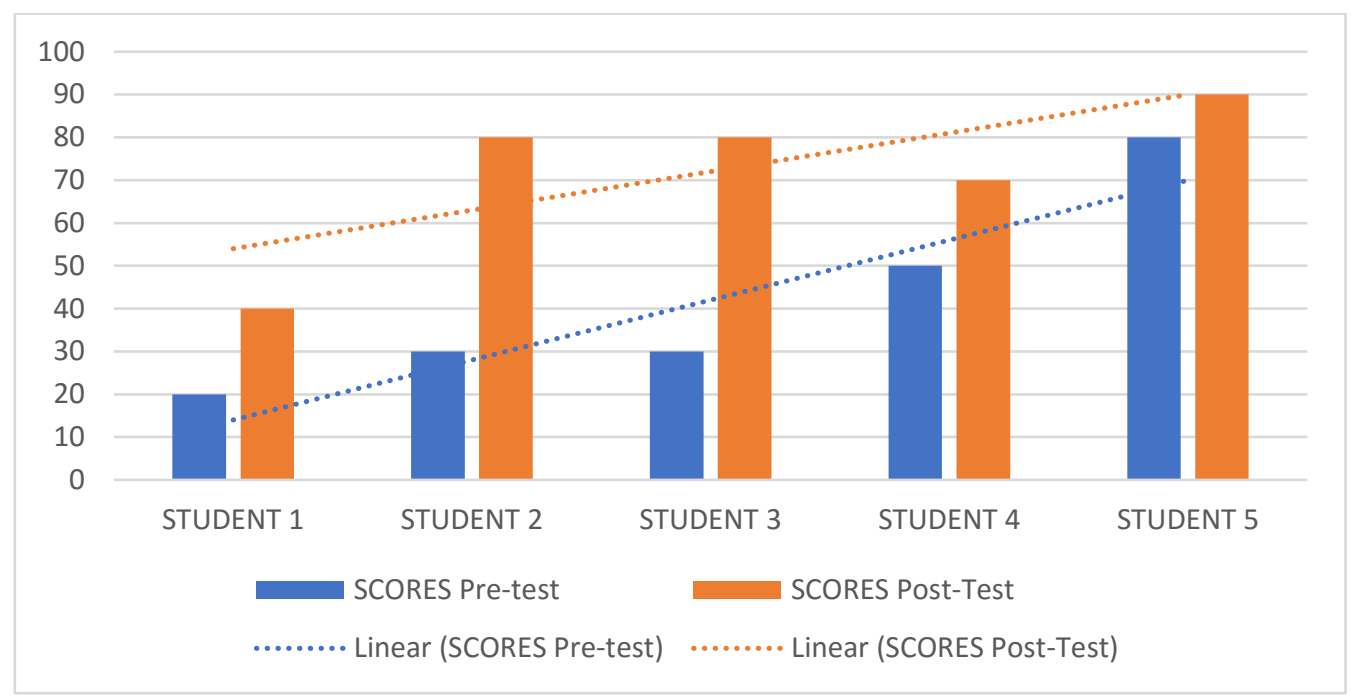

Figure 2: VTT performance for students who have prior knowledge with treatment

The third group of students consisted of students who did not have prior knowledge of basic engineering from secondary school but were exposed to a treatment using the solid model, this group had a lower score of $20 \%$ and a higher score of $60 \%$ in the pre-test, for the post-test, they had the lowest score of $40 \%$ and the highest score of $90 \%$ as presented in figure 3 .

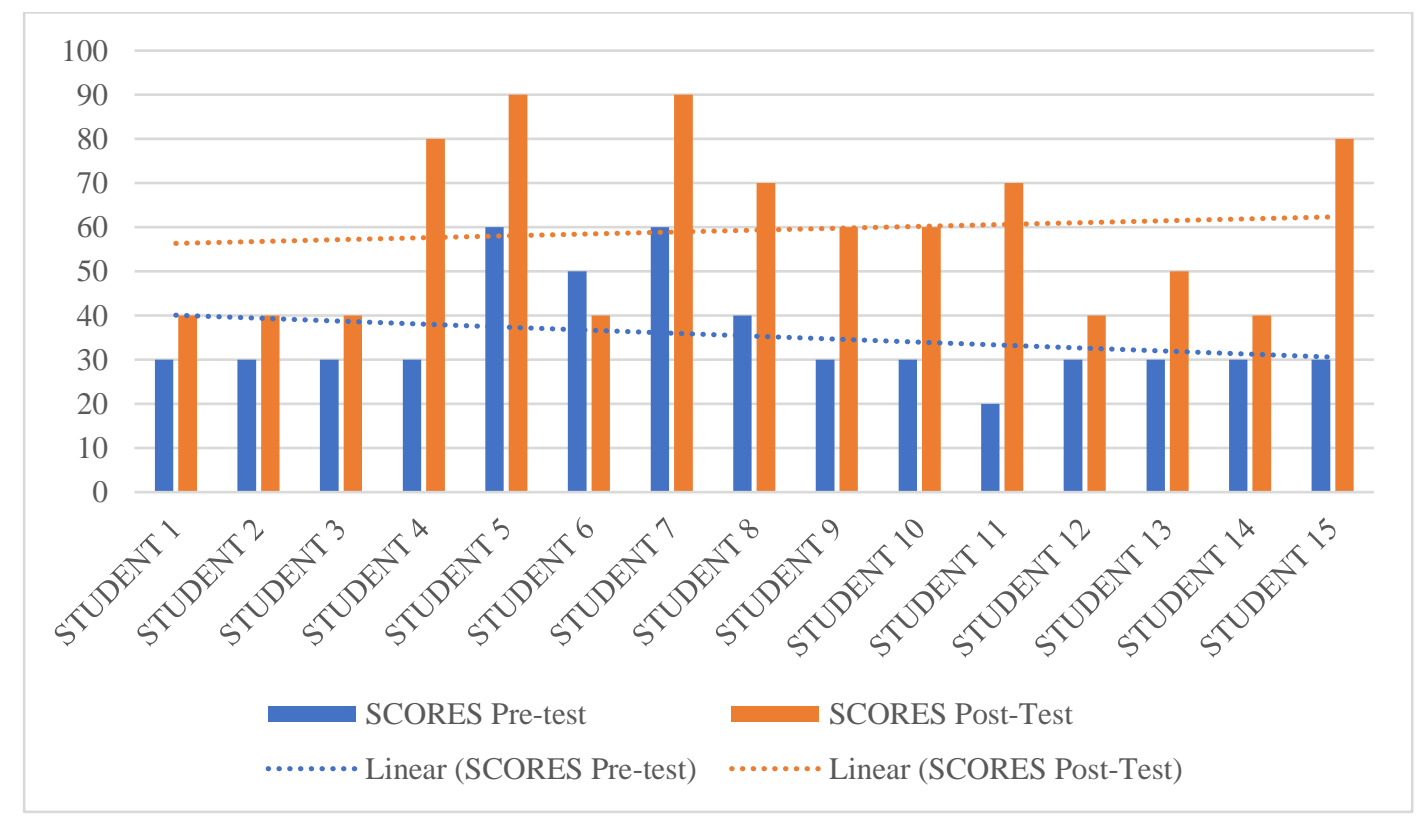

Figure 3: VTT performance for students who don't have prior knowledge with treatment 
Table 1: Mean score of VTT of each group statistic differences

\begin{tabular}{lccccc}
\hline Test: VTT & Prior knowledge & $\begin{array}{c}\text { Prior knowledge } \\
\text { without } \\
\text { treatment }\end{array}$ & with treatment & $\begin{array}{c}\text { Without prior } \\
\text { knowledge with } \\
\text { treatment }\end{array}$ & \\
\hline \multirow{3}{*}{ Pre-test } & $\mathrm{n}$ & 8 & 5 & 12 & \\
& $\mathrm{M}$ & 45.00 & 42.00 & 35.33 & $\mathrm{P}<0.05$ \\
& $\mathrm{SD}$ & 16.036 & 23.875 & 11.872 & \\
\hline Post-test & $\mathrm{n}$ & 8 & 5 & 12 & \\
& $\mathrm{M}$ & 65.00 & 72.00 & 59.33 & $\mathrm{P}>0.05$ \\
& $\mathrm{SD}$ & 13.093 & 19.235 & 19.445 & \\
\hline
\end{tabular}

\section{DISCUSSION}

In the level of prior knowledge, there were three groups for assessment, these groups were students who had prior knowledge without treatment, students who have prior knowledge with treatment, and students who don't have prior knowledge with treatment. Comparing these three groups will show the level of importance of spatial ability skills hence showing the level of significant improvement of spatial ability skills between those who had prior knowledge and those who don't

According to the results from the pre-test, it can be said that Kaduna state college of education first-year students of the department of technical education have low spatial ability skills in basic engineering drawing. The mean, standard deviations of spatial visualization ability and statistical difference of each group are analyzed in terms of descriptive statistic which is presented in Table 1 above.

Further investigating the level of significant improvement of the spatial ability skill of each group, a posttest was administered to the students after receiving a treatment using a solid pair model. The results revealed that student who had prior knowledge of basic engineering drawing from secondary school who were taught using the conventional method at post-test without treatment had a mean score $65.00(\mathrm{SD}=13.093)$, the students who had prior knowledge and received treatment had a mean score $72.00(\mathrm{SD}=19.235)$ while those without prior knowledge with a solid pair model treatment had a mean score of $59.33(\mathrm{SD}=19.445)$.

The result of this study shows that first-year students who were enrolled in the first semester in the department of technical education had challenge in picture a spatial model, the projections reconstruction, and representation. This finding is in contrast to Kok and Bayaga, (2019) who found that engineering and technology students in their first year of study do have challenges in engineering drawing which is attributed to poor spatial ability skills.

To further investigate whether there is any significant improvement of spatial ability skills, the result of the post-test, indicated there was no significant difference because all the three groups had a high mean score above 50\%. Construct of knowledge using a solid pair model according to Lord (1985) is a cognitive process that has to do with several mental visual models. During the post-test class activities using the solid pair model, the cognitive system of the learner is perceived with an external picture at first instance through the eye. The students then began to process some visual models which enable them to construct a mental pictorial image within working memory. This finding aligns with Ambozas, (2018) who stated that visual models enable an engineer to communicate an idea on drawing paper and software tools. Hence, Bosnyák and Nagy-Kondor (2008) emphasized that a solid pair method (3D) can be 
of great help in the teaching and learning of basic engineering drawing as revealed from the class activities between the control and experimental group, it is much easier to picture and reflect the various view of a solid using a solid pair model. The student without prior knowledge who received treatment and those with prior knowledge who also received treatment in the experimental group had higher performance and ability of the construction of knowledge using visual models and cognitive process of visualization as reflected in the research of (Fleeson et al., 2017).

\section{CONCLUSION}

The study is aimed at improving first-year NCE technical education students of Kaduna State College of Education Gidan Waya spatial ability skills in basic engineering drawing using a solid pair model. The findings revealed that the mean performance of spatial ability skills in basic engineering drawing between the three test groups had no significant difference. This is because the students who did not have prior knowledge but received a treatment using a solid pair model performed above average. Likewise, the students with prior knowledge who were exposed to treatment using a solid model and those with prior knowledge without treatment both performed above average.

Challenges of poor spatial ability skills among first-year Technical education students of Kaduna State College of Education Gidan Waya in basic engineering drawing can be effectively improved using a solid pair model. The construct of knowledge using a solid pair model according to Mayer (2002) is a cognitive process that has to do with several mental visual models. During the class activities using the solid pair model, the cognitive system of the learner is perceived with an external picture at first instance through the eye. The students then begin to process some visual models which aids him in the construction of a mental pictorial image within working memory. By the process of sequential arrangement of mental images, the learner arranges a number set of images into a coherent mental representation which is referred to as the projection views or the pictorial model. Every skill, like the spatial ability, as well can be developed at the very beginning with a suitable teaching strategy. The findings, therefore, indicated the effectiveness of a solid pair model for improving spatial ability skills among first-year NCE technical education students cannot be overemphasized. 


\section{REFERENCES}

Adanez, G. P. and Velasco, A. D. (2004). Training visualization ability by Technical Drawing. Journal for Geometry and Graphics, 8(1), 107-115.

Alias, M., Black, T. R. and Gray, D. E. (2002). Effect of instructions on spatial visualization ability in civil engineering students. International Education Journal, 3(1), 1-12.

Ambrozas, D. (2018). The Media and Modernity: A Social Theory of the Media, In: Communication. Médias Théories, volume 18 n¹, décembre 1997. pp. 193-195;

Mohamad Sattar Rasul, Zool Hilmi Mohamed Ashari, Norzaini Azman (2015). Transforming TVET in Malaysia: Harmonizing the Governance Structure in a Multiple Stakeholder Setting Abstract, (November). RASUL/ASHARI/AZMAN/RAUF (2015) www.tvet-online.asia Issue 41

Bate, S., and Karp, N. A. (2014). A common control group - Optimising the experiment design to maximize sensitivity. PLoS ONE, 9(12), 1-12. https://doi.org/10.1371/journal.pone.0114872

Bertoline, G. R., Wiebe, E. N., Hartman, N. W., Ross, W. A. and Miller, C. L. (2013). Technical Graphics Technical Communications Graphics Communication Fourth Edition. New York, NY 10020.

Bosnyák, Á. and Nagy-Kondor, R. (2008). The spatial ability and spatial geometrical knowledge of university students majored in mathematics. Acta Didactica Universitatis Comenianae. Mathematics, (8), 1-25.

Buckley, J., Seery, N. and Canty, D. (2019). Investigating the use of spatial reasoning strategies in geometric problem solving. International Journal of Technology and Design Education, 29(2), 341-362. https://doi.org/10.1007/s10798-018-9446-3

Centre, U. A. (2011). Quasi Experimental Pre-Test and Post Test Design Health Essay. Essays, UK. (November 2013). Retrieved on $29^{\text {th }}$ November 2019 from https://www.uniassignment.com/essay-samples/health/quasiexperimental-pre-test-and-post-test-design-health-essay.php?vref=1

Fleeson, W., Jayawickreme, E., Jones, A. B. A. P., Brown, N. A., Serfass, D. G., Sherman, R. A., Mouzakitis, G. S. et al., (2017). Making Connections: Improving Spatial Abilities with Engineering Drawing Activities. Journal of Personality and Social Psychology, 1(1), 1188-1197. https://doi.org/10.1111/j.14697610.2010.02280.x

French, T. E. (1978). The Fundamentals of Engineering Drawing \& Graphic Technology, 4th Edition. Library of Congress Cataloging

Ghanat, S. T. and Brown, K. (2017). Pedagogical Techniques Employed in an Engineering Drawing Course. 2017 ASEE Zone II Conference, (Drawing Course), 1-6.

Hughes, P., Settings, T. I., Schueler, J., Stanwick, T. J., Loveder, P., Stewart, S., Mouzakitis, G. S. et al., (2017). Achieving Sustainable Economic Development in Nigeria through Technical and Vocational Education and Training: The Missing Link. International Journal of Academic Research in Business and Social Sciences, 2(3), 3914-3920. https://doi.org/10.1007/s11125-005-4263-3

Katsioloudis, P., Jovanovic, V. and Jones, M. (2014). A Comparative Analysis of Spatial Visualization Ability and 
Drafting Models for Industrial and Technology Education Students. Journal of Technology Education, 26 (1),88-101 https://doi.org/10.21061/jte.v26i1.a.6

Kok, P. J. and Bayaga, A. (2019). Enhancing Graphic Communication and Design Student Teachers' Spatial Visualisation Skills through 3D Solid Computer Modelling Enhancing Graphic Communication and Design Student Teachers' Spatial Visualization Skills through 3D Solid Computer Modelling, African Journal of Research in Mathematics, Science and Technology Education, 23:1, 52-63, https://doi.org/10.1080/18117295.2019.1587249

Korb, K. A. (2013). Reliability and Validity of the ULCA PTSD Reaction Index for DSM-IV in the Nigerian Context. Nigerian Psychological Research, 1(9), 25-33.

Kösa, T. and Karaku, F. (2010). Using dynamic geometry software Cabri 3D for teaching analytic geometry, 2, 13851389. https://doi.org/10.1016/j.sbspro.2010.03.204

Lois, N. (2017). Use of f ICT Tools for Human Performance Improvement in Technical Drawing Contents Content Delivery at $\mathrm{t}$ Secondary School Level, International Journal of Educational Research and Technology, 8(September), 25-33.

Lord, T. R. (1985). Enhancing the visuo-spatial aptitude of students. Journal of Research in Science Teaching, 22(5), 395-405. https://doi.org/10.1002/tea.3660220503

Marunić, G. and Glažar, V. (2014). Improvement and assessment of spatial ability in engineering education. Engineering Review, 34(2), 139-150.

Maudsley, G. (2009). Do we all mean the same thing by problem based: A review of the concepts and a formulation of the ground rules. Literature assessment. Academic Medicine 2009, (74): 178-185, 16.pdf.

Mayer, R. E. (2002). Rote Versus Meaningful Learning, Theory into practice, 41,4: 226-232. Retrieved on $24^{\text {th }}$ June 2010. https://doi.org/10.1207/s15430421tip4104

Medina, L., Jaime, H., Pérez, C., and Juárez, S. (2019). Developing spatial mathematical skills through 3D tools: augmented reality, virtual environments and 3D printing. International Journal on Interactive Design and Manufacturing (IJIDeM), 13(4), 1385-1399. https://doi.org/10.1007/s12008-019-00595-2

Moreno-garc1, C. F. and Moreno-garc1, C. F. (2019). New trends on digitization of complex engineering drawings, 1, 1695-1712. https://doi.org/10.1007/s00521-018-3583-1

Nagy-kondor, R. (2007). Spatial ability of engineering students, Annales Mathematicae et Informaticae 34 (2007) pp .113-122 http://www.ektf.hu/tanszek/matematika/ami

Ramona, C. (2013). Graphical Representation of Solids an Important Issue in Teaching Technical Drawing, Applied Mechanics and Materials. 371, 493-498. Retrieved on 30 $0^{\text {th }}$ August 2013 https://doi.org/10.4028/www.scientific.net/AMM.371.493

Rodriguez, J. and Rodriguez-velazquez, L. G. (2017). Spatial Visualization Skills in Courses with Graphics or Solid Modeling Content, 2017 IEEE Global Engineering Education Conference (EDUCON) (4), 1778-1781. 2528 April 2017, Athens, Greece. 
Savery, J. R. (2006). Overview of Problem-based Learning: Definitions and Distinctions, Interdisciplinary Journal of Problem-Based Learning, 1(1).: 9-20 Available at: https://doi.org/10.7771/1541-5015.1002

Serdar, T. (2015). Enhancing Spatial Visualization Skills in Engineering Drawing Course. 122nd ASEE Annual Conference \& Exposition, 26.663.1-26.663.12. https://doi.org/10.1017/CBO9781107415324.004 